\title{
HUBUNGAN PENGEMBANGAN PROFESIONALISME DAN KINERJA DOSEN DALAM MENINGKATKAN PRESTASI BELAJAR MAHASISWA
}

\author{
RAISING STUDENT ACHIEVEMENT THROUGH PROFESSIONAL DEVELOPMENT \\ AND LECTURE PERPORMANCE
}

\author{
Asep Priatna \\ Dosen STKIP - Subang \\ E-mail: asep_priatna@yahoo.co.id
}

\begin{abstract}
ABSTRAK
Penelitian ini bertujuan untuk memperoleh gambaran tentang pengembangan profesionalisme dosen yang dilakukan oleh pimpinan fakultas dan jurusan di Universitas Pasundan Bandung untuk meningkatkan kinerja dosen dalam rangka meningkatkan prestasi belajar mahasiswa.Teori-teori yang digunakan sebagai landasan penelitian ini berkaitan dengan konsep-konsep tentang pengembangan profesionalisme dosen, kinerja dosen, prestasi belajar mahasiswa, pengembangan profesionalisme dan kinerja dosen dalam peningkatan prestasi belajar mahasiswa, dan hasil-hasil penelitian yang telah dilakukan terdahulu oleh para peneliti sebelumnya.Penelitian ini menggunakan pendekatan kuantitatif dengan metode deskriptif. Data yang terkumpul melalui angket, diolah melalui program SPSS (Statistical Package for Social Science), dengan rumus yang digunakan adalah regresi. Hasil pengolahan data selanjutnya ditafsirkan sesuai dengan masalah dan tujuan penelitian. Berdasarkan hasil penelitian ditemukan bahwa pengembangan profesionalisme dosen dalam bidang pendidikan dan pengajaran mencakup pengembangan keahlian (ekspertise); disiplin; tanggungjawab, intensitas kerja; inisiatif, dan sikap jujur. Kinerja dosen dalam pendidikan dan pengajaran mencakup mempersiapkan bahan; memperbaharui dan menggunakan bahan-bahan yang aktual; memotivasi, dan membimbing mahasiswa; menggunakan metode dan media perkuliahan yang bervariasi; mendayagunakan lingkungan sebagai sumber belajar; menyediakan waktu untuk mahasiswa berkonsultasi di luar jam kuliah; menghadiri setiap jadwal perkuliahan, dan memanfaatkan perkuliahan untuk mencapai tujuan secara optimal. Prestasi belajar mahasiswa Semester VI 2002-2003 Fakultas Keguruan, Fakultas Teknik, dan Fakultas Ekonomi Universitas Pasundan Bandung termasuk dalam kategori baik.
\end{abstract}

Kata Kunci : pengembangan profesionalisme, kinerja dosen, prestasi belajar

\begin{abstract}
This study aims to gain an overview of the professional development of lecturers conducted by leaders of faculties and departments at the University of Pasundan Bandung to improve the performance of lecturers in order to improve the learning achievement of students. Theories used as the basis of this research related to the concepts of professional development of lecturers, faculty performance, student achievement, professional development and faculty performance in improving student achievement, and the results of previous research conducted by previous researchers. This research used quantitative approach with descriptive methods. Data was collected using questionnaires, and processed with SPSS (Statistical Package for Social Science). The statistical formula used in this study was regression formula. After that, data was processed in accordance with the problem and objectives of the research. It was found that the professional development of lecturers in the field of education and teaching included the development of expertise ; discipline; responsibilities, work intensity; initiative, and impartiality. Lecturer's performance in education and teaching faculty included and not limited to preparing materials; renewing and using actual materials; motivating, and providing guidance for students; using methods and varied media lectures; using the environment as a learning resource; providing time for students to consult outside of class hours; attending every scheduled lectures, and taking advantage of classes to optimize goals. The achievement of students in Semester VI 2002-2003 from Teaching Faculty, Faculty of Engineering, and Faculty of Economics, University of Pasundan Bandung was considered to be in good category.
\end{abstract}

Keywords: professional development, lecturer performance, learning achievement 


\section{PENDAHULUAN}

Dalam Undang-Undang Republik Indonesia Nomor 20 Tahun 2003, Bab II Pasal (3) dikemukakan bahwa: Pendidikan nasional berfungsi mengembangkan kemampuan dan membentuk watak serta peradaban bangsa yang bermartabat dalam rangka mencerdaskan kehidupan bangsa, bertujuan untuk berkembangnya potensi peserta didik agar menjadi manusia yang beriman dan bertakwa kepada Tuhan Yang Maha Esa, berahlak mulia, sehat, berilmu, cakap, kreatif, mandiri, dan menjadi warga negara yang demokratis, serta bertanggung jawab. Kemudian, ketentuan yang mengatur tentang pendidikan tinggi yang di dalamnya terdapat unsur dosen, ialah Peraturan Pemerintah (PP) nomor 60 tahun 1999. Aspek terpenting yang berkaitan langsung dengan pengembangan profesionalisme dosen untuk mengupayakan peningkatan kualitas lulusan sebuah perguruan tinggi yaitu hal yang berkaitan dengan tujuan diselenggarakannya pendidikan tinggi (Marzano, R. J., Waters \& McNulty, 2016).

Menurut Huffman, Thomas, \& Lawrenz (2013) Berbicara tentang lulusan sebuah perguruan tinggi, tidak akan bisa terlepas dari, aktivitas tenaga pengajar yang biasa disebut dosen. Dikatakan demikian, mengingat pada saat terjadinya proses pendidikan di lingkungan perguruan tinggi, dosen itulah yang berinteraksi langsung dengan mahasiswa yang menjadi calon lulusan perguruan tinggi yang bersangkutan. Kegiatan belajar-mengajar (KBM) atau aktivitas perkuliahan yang diselenggarakan oleh sebuah lembaga pendidikan tinggi nampaknya banyak didominasi oleh interaksi antara dosen dan mahasiswanya.

Bahkan dari hasil beberapa catatan testimoni baik dari surat kabar maupun media elektronik dapat disimpulkan adanya pendapat para pakar pendidikan yang mengemukakah bahwa keberhasilan pendidikan di perguruan tinggi relative bergantung pada tiga komponen utama yaitu mahasiswa itu sendiri, dosen, dan institusinya. Hal yang disebutkan terakhir itu yakni institusi, meliputi fasilitas yang disediakan, sarana dan prasarana yang diperuntukan bagi kelengkapan proses pendidikan maupun faktor manajemennya (Deborah Reed, 2015; Darling-Hammond \& Wei, 2016).

Dengan demikian peran dosen akan terasa cukup signifikan dalam "mencetak" lulusannya. Jadi bila dosen tidak memiliki kredibilitas atau kemampuan yang memadai, maka kegiatan pendidikan tidak akan bisa berjalan ideal, yang mana lulusannya pun tidak akan berkualitas dan atau sesuai dengan yang diharapkan. Jika dikaitkan dengan kondisi saat ini serta bukti yang sudah membumi bahwa lulusan perguruan tinggi Indonesia kurang mempunyai kemampuan untuk bersaing atau tidak memiliki keunggulan kompetitif disaat tingkat persaingan sangat tajam dan tuntutan perkembangan teknologi semakin tinggi (Mizell, 2014).

Jelaslah, unsur dosen dalam suatu tataran pendidikan di perguruan tinggi tidak dapat diabaikan, bahkan sekarang sudah memerlukan perhatian cukup serius untuk terus dikembangkan kemampuannya. Banyak cara untuk mengembangkan potensi setiap dosen. Namun demikian langkah awal yang harus dikaji ialah penyediaan data yang tepat untuk menjadi bahan kajian agar proses pengembangan tadi dapat menghasilkan sesuatu yang sesuai dengan tuntutan profesi (Moore, Kochan, Kraska, \& Reames, 2015).

Kondisi obyektif kini menunjukkan bahwa tidak sedikit perguruan tinggi terutama perguruan tinggi swasta (PTS) yang mempunyai dosen masih jauh dari harapan baik secara kuantitatif maupun secara kualitatif. Buktinya; ada beberapa data yang pemah terungkap pada berbagai penelitian mengenai dosen seperti yang diungkapkan oleh (Mizell, 2014) dalam penelitiannya mengenai "Strategi Pengembangan Dosen Tetap di Universitas Siliwangi yang mengemukakan: (1) Rasio antara dosen dan mahasiswa belum sepenuhnya terpenuhi; (2) 
Pengadaan dosen untuk beberapa Perguruan Tinggi Swasta (PTS) yang masih mengalami hambatan-hambatan; (3) Jumlah dosen yang berpendidikan S2 dan S3 masih bervariasi dan pada umumnya belum memadai sesuai dengan kebutuhan; (4) Relevansi latar belakang pendidikan keilmuan seorang dosen dengan mata kuliah yang diberikan masih relatif belum terpenuhi; dan (5) Pembinaan terhadap dosen-dosen muda masih bervariasi, ada yang sudah baik dan ada yang masih kurang (Helen Timperley, Wilson, Barrar, \& Fung, 2017).

Imbas dari ke-lima masalah sebagaimana disebutkan itu tentu saja akan sampai pada kualitas lulusan. Artinya, jika masalah itu tidak ditangani dengan baik, niscaya akan menghasilkan lulusan yang tidak berbobot secara sosial-edukatif maupun secara sosialekonomis Keterangan ini memberikan indikasi adanya usaha yang harus dilakukan oleh suatu perguruan tinggi dalam pengembangan SDM-nya, tepatnya tenaga pengajar atau dosen guna meningkatkan kualitas pendidikan secara keseluruhan khususnya pada satuan pendidikan di tingkat mikro (DEECD 2014; Roberts, 2015).

Di antara sekian banyak PTS, ada beberapa yang mempunyai komitmen terhadap peningkatan mutu lulusan. Karenanya, PTS-PTS tersebut selalu mengupayakan peningkatan mutu tersebut melalui berbagai komponen manajemen. Hal ini didasari oleh suatu pertimbangan penting bahwa lulusan PTS yang bersangkutan umumnya akan mempunyai profesi di bidangnya, bahkan tidak jarang yang langsung jadi seorang profesional. Berangkat dari kenyataan ini; bila lulusan PTS tersebut berkualitas rendah, maka akan berdampak pada rendahnya mutu pendidikan secara lebih luas. Namun sebaliknya; jika kualitas lulusan tadi tinggi, tentunya akan berdampak positif bagi terciptanya kualitas pendidikan dalam konteks yang lebih luas lagi (The Sutton Trust, 2015)

\section{METODE PENELITIAN}

Metode penelitian yang digunakan adalah metode deskriptif kuantitatif. Metode kuantitatif dilakukan melalui pendekatan korelasional yang digunakan untuk proses pengujian atas hipotesis penelitian yang diajukan, yaitu sejauh mana Variasi pada satu faktor berkaitan dengan variasi pada faktor lainnya. Metode penelitian yang digunakan ini diharapkan mampu mengungkapkan permasalahan yang diteliti secara sistematis. Data yang diperoleh, selaras dengan operasionalisasi variabel baik ditinjau dari ukuran dan skala, maupun jenisnya. Data dalam penelitian ini dapat dikelompokkan pada data jenis data deskrit kontinu. Oleh sebab itu setiap data yang diperoleh terlebih dahulu diklasifikasi dan diolah menjadi satu kelas data interval (Broad \& Evans, 2016).

Jenis data yang diperlukan dalam penelitian ini dapat diidentifikasikan sebagai berikut: (a) Data tentang pengembangan profesionalisme dosen yang dilakukan oleh pimpinan fakultas, yang mencakup peningkatan kualitas pendidikan dan pengajaran; (b) Data tentang peningkatan kinerja dosen sebagai hasil dari pengembangan profesionalisme yang dilakukan oleh pimpinan fakultas, yang mencakup peningkatan kinerja dalam bidang pendidikan dan pengajaran; dan (c) Data tentang prestasi belajar mahasiswa, yang mencakup hasil studi mahasiswa dalam semester keenam, yang tertera dalam kartu hasil studi (KHS).

Sumber data dalam penelitian ini, diambil dari sumbernya dengan dua carayaitu, langsung (primer) dan tidak langsung (sekunder) sebagai informasi tambahan atau pelengkap yang diambil dari pihak-pihak berwenang dan kompeten. Sumber data primer adalah para pimpinan fakultas (Dekan, Pembantu Dekan, dan Ketua Jurusan), dosen yang mengajar pada semester enam, dan dokumentasi yang memuat prestasi belajar mahasiswa (KHS) universitas pasundan Bandung. 
Populasi penelitian ini adalah seluruh mahasiswa dan dosen tetap di Universitas Pasundan Bandung, yang terdaftar secara administrasi akademik dan masih aktif melakukan kegiatan profesionalnya.Setelah data hasil penelitian terkumpul, maka langkah selanjutnya adalah melakukan analisis data Penelitian yang dilakukan ini bermaksud untuk mengungkapkan adanya hubungan atau pengaruh antara variabel bebas (independent variable) dengan variabel terikat (dependent variable). Dalam statistika, metode analisis yang sesuai dengan permasalahan tersebut adalah analisis regresi, dimana satu variabel terikat dipengaruhi oleh beberapa variabel bebasnya. Variabel bebas adalah variabel yang memberikan pengaruh pada variabel terikat, sehingga variabel terikat tidak mungkinakan muncul tanpa adanya variabel bebas. Variabel terikat adalah variabel yang diasumsikan hanya muncul karena pengaruh variabel bebas tersebut. Pada bagian sebelumnya telah ditentukan bahwa variabel terikat pada penelitian ini adalah Peningkatan Kualitas Hasil Belajar Mahasiswa (Y) sedangkan variabel bebasnya adalah Pengembangan Profesionalisme Dosen yang meliputi profesionalisme (X1), dan kinerja (Y2).

Secara matematis, hubungan fungsional antara variabel terikat (Y) dan masingmasing variabel-variabel bebas $\mathrm{X} 1$, dan $\mathrm{Y} 1$, dapat dinyatakan sebagai berikut: $Y=\beta \circ I$ $+\beta \mathrm{iXi}+\varepsilon \mathrm{i} ; \quad \mathrm{i}=1,2,3,4(1)$. Persamaan di atas disebut dengan model regresi linier multipel (Berganda). Dikatakan linier karena semua variabel yang terlibat pangkatnya satu dan dikatakan multipel karena variabel bebasnya lebih dari satu.

\section{HASIL PENELITIAN DAN PEMBAHASAN}

\section{Pengembangan Profesionalisme Dosen dalam Bidang Pendidikan dan Pengajaran}

Penelitian ini memiliki tiga variabel utama, yang terdiri atas dua belas sub variabel.
Adapun variabel yang ditampilkan dalam penelitian ini adalah variabel independent, yaitu pengembangan profesionalisme dosen (X) yang diukur berdasarkan enam sub variabel. Sub-sub variabel tersebut adalah ekspertise (X1), disiplin (X2), tanggung jawab (X3), intensitas (X4); inisiatif (X5), dan jujur (X6). Variabel dependent pertama, yaitu Kinerja dosen dalam bidang pendidikan dan pengajaran (Y1) yang diukur berdasarkan enam sub variabel. Sub-sub variabel tersebut adalah ujian $\left(\mathrm{Y}^{1}\right)$, pengembangan bahan ajar $\left(\mathrm{Y}^{2}\right)$, pembimbingan mahasiswa $\left(\mathrm{Y} 1^{3}\right)$, metodologi mengajar $\left(\mathrm{Y}^{4}\right)$; interaksi/ komunikasi dengan mahasiswa $\left(\mathrm{Y} 1^{5}\right)$, dan perkuliahan $\left(\mathrm{Y}^{6}{ }^{6}\right)$. Adapun variabel dependent kedua, yaitu prestasi belajar mahasiswa (Y2). Hasil penelitian terhadap variabel-variabel di atas dideskripsikan sebagai berikut.

Responden penelitian ini terdiri dari 15 orang pimpinan fakultas dan jurusan (Dekan, Pembantu Dekan I, dan Ketua Jurusan), 45 orang dosen, dan 90 orang mahasiswa. Latarbelakang responden berdasarkan jenis kelamin, latar belakang pendidikan, golongan kerja, pengalaman kerja di Universitas Pasundan, serta pengalaman di luar Universitas Pasundan, dideskripsikan sebagai berikut. Khusus untuk responden mahasiswa hanya dideskripsikan latar belakang berdasarkan jenis kelamin. Responden berdasarkan jenis kelamin, diperoleh hasil $89 \%$ responden pimpinan adalah lakilaki, dan sebagian kecil 20\% perempuan. Responden dosen sebagian besar 62\% lakilaki, dan sebagian kecil 38\% perempuan, sedangkan sebagian besar 52\% responden mahasiswa adalah laki-laki, dan 48\% lakilaki. Adapun latar belakang pendidikan responden meliputi $13 \%$ responden pimpinan berlatar belakang pendidikan S-3, dan $40 \%$ berlatar belakang pendidikan S-2, serta $47 \%$ berlatar belakang pendidikan SI. Sedangkan responden dosen sebagian kecil 7\% berlatar belakang pendidikan S-3, dan44\% S-2, dan 49\% sarjana S-1 
Pengembangan profesionalisme dosen dalam bidang pendidikan dan pengajaran dalam penelitian ini dikaji berdasarkan indikatorindikatornya, yaitu pengembangan keahlian (ekspertise) dosen (studi lanjut, pelatihan, seminar, dan diskusi), pengembangan disiplin (kehadiran, pemanfaatan waktu, penggunaan hadiah dan hukuman), pengembangan tanggungjawab dalam membina perkuliahan, dan pembimbingan mahasiswa, pengembangan intensitas kerja (kehadiran, dan keseriusan kerja), pengembangan inisiatif (kreatifitas, kesempatan, dan kebebasan), dan pengembangan sikap jujur (ucapan, tindakkan, dan laporan kegiatan) (DeMonte, 2013; Kárpáti, 20169). Hasil penelitian terhadap aspek-aspek tersebut dapat disajikan dalam tabel.

Tabel

Pengembangan Profesionalisme Dosen dalam Bidang Pendidikan dan Pengajaran

\begin{tabular}{clcccccccc}
\hline No & \multicolumn{1}{c}{ Pertanyaan } & SL & $\%$ & SR & $\%$ & KD & $\%$ & JR & $\%$ \\
\hline 1. & $\begin{array}{l}\text { Pengembangan keahlian (ekspertise) dosen } \\
\text { (studi lanjut, pelatihan, seminar, dan diskusi) }\end{array}$ & 12 & 80 & 2 & 13 & 1 & 7 & & \\
\hline 2 & Pengembangan disiplin (kehadiran & & & & & & &
\end{tabular}

\begin{tabular}{|c|c|c|c|c|c|c|c|c|c|}
\hline 2. & $\begin{array}{l}\text { Pengembangan disiplin (kehadiran, } \\
\text { pemanfaatan waktu, penggunaan hadiah dan } \\
\text { hukuman) }\end{array}$ & 4 & 27 & 8 & 53 & 3 & 20 & & \\
\hline 3. & $\begin{array}{l}\text { Pengembangan tanggungjawab dalam } \\
\text { membina perkuliahan, dan pembimbingan } \\
\text { mahasiswa }\end{array}$ & 8 & 53 & 4 & 27 & 3 & 20 & & \\
\hline 4. & $\begin{array}{l}\text { Pengembangan intensitas kerja (kehadiran, dan } \\
\text { keseriusan kerja| }\end{array}$ & 8 & 53 & 4 & 27 & 3 & 20 & & \\
\hline 5. & $\begin{array}{l}\text { Pengembangan inisiatif (kreatifitas, } \\
\text { kesempatan, dan kebebasan) }\end{array}$ & 7 & 47 & 3 & 20 & 3 & 20 & 2 & 13 \\
\hline 6. & $\begin{array}{l}\text { Pengembangan sikap jujur (ucapan, tindakkan, } \\
\text { dan laporan kegiatan) }\end{array}$ & 4 & 27 & 4 & 27 & 4 & 27 & 3 & 19 \\
\hline
\end{tabular}

Dari tabel di atas, nampak bahwa kegiatan yang dilakukan oleh para pimpinan (Dekan, Pembantu Dekan I, dan Ketua Jurusan) dalam pengembangan profesionalisme dosen dalambidang pendidikandanpengajaran dapat dideskripsikan sebagai berikut. Sebagian besar (80\%) pimpinan fakultas (Dekan, Pembantu Dekan I, dan Ketua Jurusan) selalu melakukan pengembangan profesionalisme dosen melalui Pengembangan keahlian (ekspertise) dosen (studi lanjut, pelatihan, seminar, dan diskusi); hanya sebagian kecil, masing-masing menyatakan sering (13\%), dan kadang-kadang (7\%).

Sebagian besar (53\%) pimpinan fakultas (Dekan, Pembantu Dekan I, dan Ketua Jurusan) sering melakukan pengembangan profesionalisme dosen melalui pengembangan disiplin (kehadiran, pemanfaatan waktu, penggunaan hadiah dan hukuman); serta sebagian kecil, masing- masing menyatakan selalu (27\%), dan kadang-kadang (20\%). Sebagian besar (53\%) pimpinan fakultas selalu melakukan pengembangan profesionalisme dosen melalui pengembangan tanggungjawab dalam membina perkuliahan, dan pembimbingan mahasiswa; hanya sebagian kecil, masingmasing menyatakan sering (27\%), dan kadang-kadang (20\%).

Sebagian besar (53\%) pimpinan fakultas (Dekan, Pembantu Dekan I, dan Ketua Jurusan) selalu melakukan pengembangan profesionalisme dosen melalui pengembangan intensitas kerja (kehadiran, dan keseriusan kerja); serta hanya sebagian kecil, masingmasing menyatakan sering (27\%), dan kadang-kadang (20\%), (47\%) pimpinan fakultas (Dekan, Pembantu Dekan I, dan Ketua Jurusan) selalu melakukan pengembangan profesionalisme dosen melalui pengembangan inisiatif (kreatifitas, 
kesempatan, dan kebebasan); serta hanya sebagian kecil, masing-masing menyatakan sering (20\%), kadang-kadang (20\%); dan jarang (13\%). Hanya sebagian kecil, masingmasing (27\%) pimpinan fakultas (Dekan, Pembantu Dekan I, dan Ketua Jurusan) selalu melakukan pengembangan profesionalisme dosen melalui pengembangan sikap jujur (ucapan, tindakkan, dan laporan kegiatan); (27\%) sering, (27\%) kadang-kadang, dan $19 \%$ ) menyatakan jarang.

\section{Kinerja Dosen dalam Bidang Pendidikan dan Pengajaran}

Kinerja dosen dalam bidang pendidikan dan pengajaran dalam penelitian ini dilihat dari faktor-faktor yang mempengaruhinya, yaitu mempersiapkan bahan ujian (harian, UTS, UAS), memeriksa dan mengembalikan hasil ujian, mempersiapkan bahan sebelum memberi kuliah, memperbaharui dan menggunakan bahan-bahan yang aktual, memotivasi mahasiswa agar mempelajari sumber lain untuk menunjang perkuliahan, membimbing mahasiswa dalam memecahkan masalah dan kesulitan belajar, menggunakan metode dan media yang bervariasi, mendayagunakan lingkungan sebagai sumber belajar, menerima kritikan dan saran dari mahasiswa sehubungan dengan perkuliahan yang dilaksanakan, menyediakan waktu untuk mahasiswa berkonsultasi mengenai matakuliah di luar jam kuliah, menghadiri setiap jadwal kegiatan perkuliahan (kehadiran $>80 \%$ ), dan memanfaatkan perkuliahan untuk mencapai tujuan secara optimal (Missouri Departement Education, 2014; Iheanachor \& Education, 2017).

Berdasarkan hasil analisis diperoleh 67\% dosen menyatakan bahwa mereka selalu mempersiapkan bahan ujian (Ujian Harian, UTS, UAS), sebagian kecil 27\% dosen menyatakan sering mempersiapkan bahan ujian, dan hanya sedikit (6\%) menyatakan kadang-kadang, 64\% dosen menyatakan bahwa mereka sering memeriksa dan mengembalikan hasil ujian, serta sebagian kecil, masing-masing 20\% menyatakan selalu mengembalikan hasil ujian, dan $16 \%$ menyatakan kadang-kadang, $71 \%$ dosen menyatakan bahwa mereka selalu mempersiapkan bahan sebelum memberi kuliah, 24\% dosen menyatakan sering mempersiapkan bahan sebelum kuliah, dan hanya sedikit (5\%) yang menyatakan kadangkadang.

Sebagian besar $(71 \%)$ dosen menyatakan bahwa mereka sering memperbaharui dan menggunakan bahan-bahan yang aktual, serta sebagian kecil, masing-masing (16\%) menyatakan selalu memperbaharui dan menggunakan bahan-bahan yang aktual, dan $13 \%$ menyatakan kadang-kadang. Dosen selalu memotivasi mahasiswa agar mempelajari sumber lain untuk menunjang perkuliahan sekitar $85 \%, \quad 13 \%$ dosen menyatakan sering, dan hanya $2 \%$ yang menyatakan kadang-kadang.

Temuan lain yaitu mengenai dosen sering membimbing mahasiswa dalam memecahkan masalah dan kesulitan belajar 53\%, 38\% menyatakan selalu, dan $9 \%$ menyatakan kadang-kadang. $44 \%$ dosen menyatakan bahwa mereka selalu menggunakan metode dan media perkuliahan yang bervariasi; masing-masing 33\% menyatakan sering, 16\% menyatakan kadang-kadang; $7 \%$ menyatakan jarang. Dosen menyatakan kadang-kadang mendayagunakan lingkungan sebagai sumber belajar 13\%, 27\% menyatakan jarang, 24\% menyatakan selalu, dan $18 \%$ menyatakan sering mendayagunakan lingkungan sebagai sumber belajar.

Dosen menyatakan jarang menerima kritikan dan saran dari mahasiswa sehubungan dengan perkuliahan yang dilaksanakan sekitar 42\%; serta sebagian kecil, masingmasing 31\% menyatakan kadang-kadang, $13 \%$ menyatakan sering, 9\% menyatakan tidak pernah, dan 5\% menyatakan selalu. Sebagian besar (56\%) dosen menyatakan sering menyediakan waktu untuk mahasiswa berkonsultasi mengenai matakuliah di luar jam kuliah; serta sebagian kecil (20\%) 
menyatakan selalu, (20\%) menyatakan kadang-kadang, dan hanya sedikit sekali (4\%) menyatakan jarang (56\%) dosen menyatakan selalu menghadiri setiap jadwal perkuliahan (kehadiran $>80 \%$ ), dan hampir separuhnya (44\%) dosen menyatakan sering. Sebagian besar (67\%) dosen menyatakan sering memanfaatkan perkuliahan untuk mencapai tujuan secara optimal, serta sebagian kecil, masing-masing (18\%) menyatakan selalu, dan (15\%) menyatakan kadang-kadang.

\section{Prestasi Belajar Mahasiswa}

Prestasi belajar yang dimaksud dalam penelitian ini adalah nilai akhir semester yang dicapai oleh para mahasiswa Semester VI 2002-2003 Fakultas Keguruan, Fakultas Teknik, dan Fakultas Ekonomi Universitas Pasundan di Bandung, yang tertera dalam Kartu Hasil Studi (KHS).Hasil analisis deskriptif menunjukkan bahwa rata-rata prestasi belajar mahasiswa Universitas Pasundan Bandung adalah 2,83, dengan IP maksimum 3,70, dan nilai minimum 1,86. Hal tersebut berarti bahwa rata-rata prestasi belajar mahasiswa Semester VI 2002-2003 Fakultas Keguruan, Fakultas Teknik, dan Fakultas Ekonomi Universitas Pasundan di Bandung termasuk dalam kategori baik (B).

\section{Hubungan antara Pengembangan Profesionalisme, Kinerja Dosen dan Prestasi Belajar Mahasiswa}

Pada bagian sebelumnya telah dideskripsikan tentang kecenderungan responden melalui analisis masing-masing variabel yang diteliti, yaitu mengenai pengembangan profesionalisme dosen, kinerja dosen dalam bidang pendidikan dan pengajaran serta prestasi belajar mahasiswa. Selanjutnya untuk mengetahui kadar besar kecilnya hubungan variabel independent (pengembangan profesionalisme dosen) terhadap variable dependent (kinerja dosen), dan kinerja dosen terhadap prestasi belajar mahasiswa dilakukan analisis berdasarkan perhitungan statistik melalui komputer, dengan SPSS
(Salazar, 2016; Nelson, 2012).

Hasil pengujian yang dilakukan melalui analisis regresi, menunjukkan bahwa koefisien regresi X dengan Yi ( $\left.{ }^{\mathrm{X}} \mathrm{X}, \mathrm{Y} 1\right)$ sebesar 0,975 (R), dengan standard error 0,586. Nilai $\mathrm{F}$ yang ditunjukkan oleh koefisien korelasi tersebut sebesar 25,480 ; dengan signifikansi (Signif F) sebesar 0,05. Dengan demikian berarti pengembangan profesionalisme dosen, yang mencakup ekspertise, disiplin, tanggung jawab, intensitas, inisiatif, dan jujur, berkontribusi positif dengan kinerja dosen dalam bidang pendidikan dan pengajaran di Universitas Pasundan Bandung. Memperhatikan koefisien regresi (R). yang ditunjukkan komputasi komputer, yaitu sebesar 0,975 dapat dinyatakan bahwa 97\% varian kinerja dosen dalam bidang pendidikan dan pengajaran di Universitas Pasundan Bandung berkaitan dengan variabel ekspertise, disiplin, tanggung jawab, intensitas, inisiatif, dan jujur (kejujuran) secara bersama-sama. Harga varian yang diketahui melalui analisis regresi itu disebut sebagai varian yang terjelaskan (explained variance). Dengan demikian, variabel ekspertise, disiplin, tanggung jawab, intensitas, inisiatif, dan jujur (kejujuran) secara bersama-sama memberikan pengaruh positif yang signifikan sebanyak $97 \%$ terhadap kinerja dosen dalam bidang pendidikan dan pengajaran di Universitas Pasundan Bandung.

Berdasarkan hasil tersebut dapat ditafsirkan sebagai berikut: 'ekspertise, disiplin, tanggung jawab, intensitas, inisiatif, dan jujur (kejujuran) secara bersama-sama memberikan pengaruh positif terhadap kinerja dosen dalam bidang pendidikan dan pengajaran di Universitas Pasundan Bandung." Nilai Beta yang ditunjukkan oleh masing-masing sub variabel tersebut adalah XI $(0,17)$, X2 $(0,16)$, X3 $(0,27)$, X4 $(0,15)$, X5 $(0,14)$, dan X6 $(0,20)$. Hal tersebut berarti pengembangan ekspertise dosen memberikan sumbangan positif sebesar $17 \%$ terhadap kinerja dosen dalam bidang pendidikan dan 
pengajaran. Pengembangan disiplin dosen memberikan sumbangan positif sebesar 16\% terhadap kinerja dosen dalam bidang pendidikan dan pengajaran. Pengembangan tanggung jawab dosen memberikan sumbangan positif sebesar $27 \%$ terhadap kinerja dosen dalam bidang pendidikan dan pengajaran. Pengembangan intensitas kerja dosen memberikan sumbangan positif sebesar $15 \%$ terhadap kinerja dosen dalam bidang pendidikan dan pengajaran. Pengembangan inisiatif kerja dosen memberikan sumbangan positif sebesar 14\% terhadap kinerja dosen dalam bidang pendidikan dan pengajaran. Pengembangan sikap jujur (kejujuran) dosen memberikan sumbangan positifsebesar $20 \%$ terhadap kinerja dosen dalam bidang pendidikan dan pengajaran. Sub variabel pembinaan profesionalisme dosen tersebut yang paling besar kontribusinya terhadap kinerja dosen dalam bidang pendidikan dan pengajaran adalah pengembangan tanggung jawab, yakni sebesar 27\%. Sedangkan yang paling kecil kontribusinya adalah pengembangan inisiatif, yakni sebesar $14 \%$.

Hasil pengujian yang dilakukan melalui analisis regresi, menunjukkan bahwa koefisien regresi YI dengan $\mathrm{Y}_{2}\left({ }^{\mathrm{r}} \mathrm{Yi}, \mathrm{Y}_{2}\right.$ sebesar 0,763 (R), dengan standard error 0,304. Nilai $\mathrm{F}$ yang ditunjukkan oleh koefisien korelasi tersebut sebesar 8,818; dengan signifikansi (Signif F) sebesar 0,05, Dengan demikian berarti kinerja dosen dalam bidang pendidikan dan pengajaran, yang mencakup ujian, pengembangan bahan ajar, pembimbingan mahasiswa, metodologi mengajar, interaksi/ komunikasi dengan dosen, dan perkuliahan berkontribusi positif dengan prestasi belajar mahasiswa Universitas Pasundan Bandung.

Berdasarkan hasil analisis data tersebut, maka hipotesis kedua yang menyatakan: Terdapat hubungan yang signifikan antara kinerja dosen dalam bidang pendidikan dan pengajaran dengan prestasi belajar mahasiswa Universitas Pasundan Bandung, dapat diterima. Memperhatikan koefisien regresi (R). yang ditunjukkan komputasi komputer, yaitu sebesar 0,763 dapat dinyatakan bahwa $76 \%$ varian prestasi belajar mahasiswa Universitas Pasundan Bandung berkaitan dengan variabel kinerja dosen dalam bidang pendidikan dan pengajaran, yang mencakup (sub variabel) pengembangan bahan ajar, pembimbingan mahasiswa, metodologi mengajar, interaksi/ komunikasi dengan dosen, dan perkuliahan secara bersama-sama. Harga varian yang diketahui melalui analisis regresi itu disebut sebagai varian yangterjelaskan (explained variance) (Goe, L., Biggers, K., Croft, 2012; Hightower et al., 2016). Dengan demikian, sub variabel pengembangan bahan ajar, pembimbingan mahasiswa, metodologi mengajar, interaksi atau komunikasi dengan dosen, dan perkuliahan secara bersama-sama memberikan pengaruh positif yang signifikan sebanyak $76 \%$ terhadap prestasi belajar mahasiswa Universitas Pasundan Bandung. Dengan demikian, dapat ditafsirkan sebagai berikut: "Pengembangan bahan ajar, pembimbingan mahasiswa, metodologi mengajar, interaksi/komunikasi dengan dosen, dan perkuliahan secara bersamasama memberikan pengaruh positif terhadap prestasi belajar mahasiswa Universitas Pasundan Bandung."

Jika dilihat dari besarnya sumbangan yang diberikan oleh sub-sub variabel pada kinerja dosen dalam bidang pendidikan dan pengajaran (pengembangan bahan ajar, pembimbingan mahasiswa, metodologi mengajar, interaksi/komunikasi dengan dosen, dan perkuliahan), maka dapat dijelaskan sumbangan dari masing-masing sub variabel tersebut sebagai berikut. Nilai Beta yang ditunjukkan oleh masing-masing sub variabel tersebut adalah $\mathrm{Y}^{1}(0,13)$, $\mathrm{Y}^{2}(0,24), \mathrm{Y} 1^{3}(0,18), \mathrm{Y} 1^{4}(0,12), \mathrm{Y} 1^{5}$ $(0,13)$, dan $Y 1^{6}(0,14)$. Hal tersebut berarti kinerja dosen dalam hal ujian memberikan sumbangan positif sebesar 13\% terhadap prestasi belajar mahasiswa. Kinerja dosen dalam pengembangan bahan ajar memberikan sumbangan positif sebesar $24 \%$ 
terhadap prestasi belajar mahasiswa. Kinerja dosen dalam pembimbingan mahasiswa memberikan sumbangan positif sebesar $18 \%$ terhadap prestasi belajar mahasiswa. Kinerja dosen dalam metodologi mengajar memberikan sumbangan positif sebesar $12 \%$ terhadap prestasi belajar mahasiswa. Kinerja dosen dalam interaksi/komunikasi dengan mahasiswa memberikan sumbangan positif sebesar $13 \%$ terhadap prestasi belajar mahasiswa. Kinerja dosen dalam perkuliahan memberikan sumbangan positif sebesar $14 \%$ terhadap prestasi belajar mahasiswa.

Dari berbagai sub variabel kinerja dosen dalam bidang pendidikan dan pengajaran tersebut yang paling besar kontribusinya terhadap prestasi belajar mahasiswa adalah pengembangan bahan ajar, yakni sebesar $24 \%$. Sedangkan yang paling kecil kontribusinya adalah metodologi mengajar, yakni sebesar 12 \%sebagai Upaya Meningkatkan Prestasi Belajar Mahasiswa (Kajian pada Mahasiswa Semester VI 2002-2003 Fakultas Keguruan dan Ilmu Pendidikan, Fakultas Teknik, dan Fakultas Ekonomi Universitas Pasundan di Bandung), dapat dirangkum sebagai berikut yaitu prestasi belajar mahasiswa Semester VI 2002-2003 Fakultas Keguruan, Fakultas Teknik, dan Fakultas Ekonomi Universitas Pasundan Bandung termasuk dalam kategori baik (B); dengan rata-rata 2,83, IP maksimum 3,70 , dan nilai minimum 1,86 .

Pengembangan ekspertise dosen memberikan sumbangan positif sebesar 17\% terhadap kinerja dosen dalam bidang pendidikan dan pengajaran. Pengembangan disiplin dosen memberikan sumbangan positif sebesar 16\% terhadap kinerja dosen dalam bidang pendidikan dan pengajaran. Pengembangan tanggung jawab dosen memberikan sumbangan positif sebesar 27\% terhadap kinerja dosen dalam bidang pendidikan dan pengajaran. Pengembangan intensitas kerja dosen memberikan sumbangan positif sebesar $15 \%$ terhadap kinerja dosen dalam bidang pendidikan dan pengajaran. Pengembangan inisiatif kerja dosen memberikan sumbangan positif sebesar 14\% terhadap kinerja dosen dalam bidang pendidikan dan" pengajaran. Pengembangan sikap jujur (kejujuran) dosen memberikan sumbangan positif sebesar $20 \%$ terhadap kinerja dosen dalam bidang pendidikan dan pengajaran.Variabel pengembangan profesionalisme dosen yang paling besar sumbangannya terhadap kinerja dosen dalam bidang pendidikan dan pengajaran adalah pengembangan tanggung jawab, sedangkan yang paling kecil sumbangannya adalah pengembangan inisiatif.

Kinerja dosen dalam ujian berkontribusi positif yaitu sebesar 13\% terhadap prestasi belajar mahasiswa. Kinerja dosen dalam pengembangan bahan ajar memberikan sumbangan positif sebesar $24 \%$ terhadap prestasi belajar mahasiswa. Kinerja dosen dalam pembimbingan mahasiswa memberikan sumbangan positifsebesar $18 \%$ terhadap prestasi belajar mahasiswa. Kinerja dosen dalam metodologi mengajar memberikan sumbangan positif sebesar $12 \%$ terhadap prestasi belajar mahasiswa. Kinerja dosen dalam interaksi/komunikasi dengan mahasiswa memberikan sumbangan positif sebesar $13 \%$ terhadap prestasi belajar mahasiswa. Kinerja dosen dalam perkuliahan memberikan sumbangan positif sebesar 14\% terhadap prestasi belajar mahasiswa. Dari berbagai sub variabel kinerja dosen dalam bidang pendidikan dan pengajaran tersebut yang paling besar kontribusinya terhadap prestasi belajar mahasiswa adalah pengembangan bahan ajar, sedangkan yang paling kecil kontribusinya adalah metodologi mengajar.

\section{SIMPULAN}

Berdasarkan hasil penelitian maka diperoleh kesimpulan sebagai berikut: 1) Kegiatan-kegiatan yang dilaksanakan untuk mengembangkan profesionalisme dosen di Universitas Pasundan Bandung Adalah mengembangkan Ekspertise, Disiplin, Tanggung Jawab, Intensitas Kerja, Inisiatif, 
dan Sikap Jujur (kejujuran) dosen dalam melaksanakan tugasnya. 2) Kinerja dosen dalam bidang pendidikan dan pengajaran mencakup pengembangan bahan ajar, pembimbingan mahasiswa, metodologi mengajar; interaksi/komunikasi dengan mahasiswa, dan melakukan kegiatan perkuliahan. 3) Prestasi belajar mahasiswa Universitas pasundan bandung, pada semester enam 2002/2003, berkisar antara 1,86 (terendah) dan 3,70 (tertinggi). Rata-rata prestasi belajar mahasiswa 2,83; termasuk dalam kategori baik (b). 4) pengembangan profesionalisme dosen, baik yang menyangkut Ekspertise, Disiplin, Tanggung Jawab, Intensitas Kerja, Inisiatif, maupun sikap Sikap Jujur, baik secara terpisah maupun secara serempak memberikan sumbangan yang positif terhadap kinerja dosen dalam bidang pendidikan dan pengajaran.

\section{REKOMENDASI}

Untuk rekomendasi dari penelitian ini, bahwa profesionalisme dosen harus lebih dikembangkan baik menyangkut ekspertise, disiplin, tanggung jawab, intensitas kerja, inisiatif, maupun sikap. Karena profesionalisme dosen akan meningkatkan kinerjanya dalam memberikan pengajaran terhadap mahasiswa dan pada akhirnya akan meningkatkan prestasi belajar mahasiswa. Pengembangan profesionalisme guru selain berasal dari internal bisa juga ditingkatkan melalui seminar-seminar, sehingga pengembangan dosen dalam pemahaman ilmu yang di milikinya sikap jujur, baik secara terpisah maupun secara serempak memberikan sumbangan yang positif terhadap kinerja dosen dalam bidang pendidikan dan pengajaran. Peningkatan prestasi mahasiswa akan berdampak baik pada prestasi universitas dan prestasi Negara.

\section{DAFTAR RUJUKAN}

Broad, K., \& Evans, M. (2016). A Review of Literature On Professional Development Content And Delivery Modes For Experienced Teachers. Initial Teacher Education Program, 2(10).

Darling-Hammond, L., \& Wei, R. C. (2016). Professional Learning in the Learning Profession : A Status Report on Teacher Development in the United States and Abroad. National Staff Development Council, 3(February), 1-32.

Deborah Reed. (2015). Why Is Professional Development So Important? U.S Departement of Education, pp. 1-12.

DEECD. (2014). Professional Practice and Performance for Improved Learning: Performance and Development (Vol. 2). Departement of Education and Early Childhood Development.

DeMonte, J. (2013). High-Quality Professional Development for Teachers : Supporting Teacher Training To Improve Student Learning. Center for American Progress |.

Goe, L., Biggers, K., Croft, A. (2012). to Professional Development: Focusing on Improving Teaching and Learning Research \& Policy Brief. Research in Science Education, 2(2), 40-49.

Helen Timperley, Wilson, A., Barrar, H., \& Fung, I. (2017). Teacher Professional Learning and Development. Ministry of Education (Vol. 33).

Hightower, A. M., Delgado, R. C., Lloyd, S. C., Wittenstein, R., Sellers, K., \& Swanson, C. B. (2016). Improving Student Learning By Supporting Quality Teaching: A Survey of School Finance Key Issues, Effective Strategies. Bethesda,

Huffman, D., Thomas, K., \& Lawrenz, F. (2013). Relationshipbetween professional development, teachers' instructional practices, and the achievement of students in science and mathematics. School Science and Mathematics.

Iheanachor, O. U., \& Education, M. (2017). the Influence of Teachers 'Background, Professional Development and Teaching Practices on Students 'Achievement in. University of South Africa.

Kárpáti, A. (20169). Teacher Training And Professional Development. In Green Book : For The Renewal Of Public Education In Hungary (pp. 203-226). Nrew York: McKin- sey \& Company. 
Marzano, R. J., Waters, T., \& McNulty, B. (2016). Raising Student Achievement Through Professional Development. Journal of Elementary Science Education, 1(1), 1-12.

Missouri Departement Education. (2014). Teacher Standards. In Missouri Departement Journal (Vol. 2, pp. 340349).

Mizell, H. (2014). Why Professional Development Matters. Learning Forward (NJ), 3(2), 1-28.

Moore, S. D., Kochan, F. K., Kraska, M., \& Reames, E. H. (2015). Professional development and student achievement in high poverty schools: Making the connection. International Studies in Educational Administration, 39(2), 65-80.

Nelson, J. A. (2012). Effects of Teacher Evaluations on Teacher Effectiveness and Student Achievement. Education Journal, 1(2), 45-56.

Roberts, M. (2015). Inproving Student Achievement through Professional Learning Communities. University of Nebraska.

Salazar, L. (2016). Theater teacher assessment and evaluation : The National Education Association's Framework for Transforming Education Systems to Support Effective Teaching and Improve Student Learning. Arts Education Policy Review, 98(1), 27-38.

The Sutton Trust. (2015). Improving the impact of teachers on pupil achievement in the UK-interim findings. 